\title{
Rac1 modulates acute and subacute genotoxin-induced hepatic stress responses, fibrosis and liver aging
}

\author{
A Bopp ${ }^{1,2}$, F Wartlick ${ }^{1,2}$, C Henninger ${ }^{1}$, B Kaina ${ }^{2}$ and G Fritz ${ }^{*, 1}$
}

To investigate the importance of the Ras-homologous GTPase Rac1 for the hepatic response to genotoxic insults and liver aging, rac1 was deleted in liver of mice by Mx1-Cre-based recombination. Knockout of rac1 caused complex changes in basal as well as doxorubicin and ionizing radiation-induced mRNA expression of various genotoxic stress response-related genes, including hspa1b, rad51, wrn and xpc. Rac1 deletion protected the liver from acute toxicity following doxorubicin treatment. Moreover, the level of S139 phosphorylated histone H2AX ( $\gamma \mathrm{H} 2 \mathrm{AX})$, which is indicative of DNA damage, and mRNA expression of pro-inflammatory (IL-6) and pro-fibrotic (CTGF, TGF $\beta, \alpha$ SMA) factors were mitigated in rac1 knockout animals. By contrast, lack of rac1 promoted subacute hepatotoxicity, which was determined 3 weeks after injection of multiple low doses of doxorubicin by assaying the $\gamma \mathrm{H} 2 \mathrm{AX}$ level, mitotic index and pro-fibrotic gene expression. Regarding ionizing radiation, rac1 deficiency had no major effects on DNA damage induction or acute pro-inflammatory and pro-fibrotic stress responses. Mice lacking hepatic rac1 for extended period of time ( 15 months) revealed increased mRNA expression of fibrosis-related factors (CTGF, TGF $\beta$, collagen, MMP1) and fibrotic tissue remodeling. In addition, protein expression of the senescence marker p16 was enhanced in the absence of rac1. Taken together, the data provide evidence that Rac1 is required for doxorubicin-induced DNA damage induction. It is also involved in both the acute and delayed inflammatory and fibrotic stress response in the liver following doxorubicin, but not ionizing radiation, treatment and, furthermore, protects against endogenous liver aging.

Cell Death and Disease (2013) 4, e558; doi:10.1038/cddis.2013.57; published online 21 March 2013

Subject Category: Experimental Medicine

Membrane-bound low molecular weight GTPases of the Rho (Rho $=$ Ras homologous) family play pivotal roles in the regulation of a variety of cellular functions, including proliferation, gene expression, transformation and apoptosis as well as actin cytoskeleton-related functions such as cell motility and cell adhesion. ${ }^{1,2}$ Among the Rho family, the Ras-related C3 botulinum substrate 1 (Rac1) is a key regulator of stressactivated protein kinases (SAPK/JNK), p38 kinase and extracellular regulated kinases (ERK), ${ }^{3,4} \mathrm{NADPH}$ oxidase $^{5}$ as well as numerous transcription factors including NF- $\kappa \mathrm{B},{ }^{6}$ $\mathrm{AP} 1,{ }^{7} \mathrm{Smad}^{8,9}$ and Stat proteins. ${ }^{10}$ Moreover, Rac1 signaling regulates mitosis and meiosis, ${ }^{11,12}$ which is in line with its recently reported nuclear localization and interaction with proteins of the replication machinery. ${ }^{13}$ Rac1 is also highly important for tumor progression and metastasis as it controls cell-cell adhesion and epithelial-to-mesenchymal transition (EMT). ${ }^{14}$ Rac1 affects Ki-Ras mediated lung carcinogenesis ${ }^{15}$ and cross-talks with the MLL-AF9 oncogene, which is important for development of acute myeloid leukemia. ${ }^{16,17}$ Using transgenic technology it has further been shown that Rac1 is essential for B-cell development and signaling. ${ }^{18}$ Rac1 affects cell spreading and membrane ruffling, but does not influence the motility of macrophages. ${ }^{19}$

Bearing in mind the aforementioned key functions of Rho GTPases in the onset and progression of malignant diseases, therapeutic targeting of members of the family of Rho

\footnotetext{
${ }^{1}$ Department of Toxicology, Heinrich Heine University Düsseldorf, Moorenstrasse 5, Düsseldorf D-40225, Germany and ${ }^{2}$ Department of Toxicology, University Medical Center Mainz, Obere Zahlbacher Str. 67, Mainz D-55131, Germany

*Corresponding author: G Fritz, Department of Toxicology, Heinrich Heine University Düsseldorf, Moorenstrasse 5, Düsseldorf D-40225, Germany. Tel: + 4921 1811 3022; Fax: + 4921181 3013; E-mail: fritz@uni-duesseldorf.de

Keywords: small GTPases; Rac1; genotoxic stress response; hepatotoxicity; fibrosis; aging

Abbreviations: Alb, albumin; AML, acute myeloid leukemia; AP1, activator protein 1; Ccne1, cyclin E1; cdkn1a, cyclin-dependent kinase inhibitor $1 \mathrm{~A}$; c-Fos, Fos protooncogene; c-Jun, Jun proto-oncogene; Cre, cyclization recombinase; CTGF, connective tissue growth factor; Cxcr4, chemokine (C-X-C motif) receptor 4; DAPI, 4',6diamidino-2-phenylindol; DDR, DNA damage response; DSBs, DNA double-strand breaks; EMT, epithelial-to-mesenchymal transition; ERK2, extracellular signalregulated kinase 2; GAPDH, glyceraldehyde 3-phosphate dehydrogenase; GLDH, glutamate dehydrogenase; GPT, glutamate pyruvate transaminase; gstm1, glutathione-S-transferase mu 1; H2AX, H2A histone family member X; hmox-1, heme oxygenase 1; hspa1b, heat shock 70 kDa protein 1B; IL-6, interleukin-6; IR, ionizing radiation; JNK, c-Jun N-terminal kinase; mdr-1, multidrug resistance gene 1; MMP1, matrix metalloporteinase 1; MPO, myeloperoxidase; mrp-1, multidrug resistance-related gene 1; Mx1, myxovirus resistance 1; NADPH, nicotinamide adenine dinucleotide phosphate; NF- $\kappa \mathrm{B}$, nuclear factor $\kappa \mathrm{B}$; Nrf2, nuclear factor (erythroid-derived 2)-like 2; p16, cyclin-dependent kinase inhibitor 2A; p38, p38 mitogen-activated protein kinases; PCR, polymerase chain reaction; pH3, S10 phosphorylated histon $\mathrm{H3}$; poly(l:C), polyinosinic:polycytidylic acid; qRT, quantitative reverse transcription; Rac, Ras-related C3 botulinum toxin substrate; rad51, DNA repair protein RAD51 homolog 1; Rho, Ras homologous; Rock, Rho-associated coiled-coil forming protein kinase; SAPK, stress-activated protein kinase; Stat, signal transducer and activator of transcription; TBI, total body irradiation; TGF $\beta$, transforming growth factor $\beta$; TIMP2, tissue inhibitor of metalloproteinases 2; Topo2 $\beta$, topoisomerase II $\beta$; TOR, target of rapamycin; TUNEL, terminal deoxynucleotidyl transferase dUTP nick end labeling; wee1, human Wee1-like protein kinase; wrn, Werner syndrome ATP-dependent helicase; xpc, xeroderma pigmentosum complementation group C; $\alpha \mathrm{SMA}, \alpha$ smooth muscle actin; $\gamma \mathrm{H} 2 \mathrm{AX}$, S139 phosphorylated $\mathrm{H} 2 \mathrm{AX}$

Received 30.10.12; revised 02.1.13; accepted 04.2.13; Edited by M Federici
} 
GTPases is suggested to improve anticancer therapy. ${ }^{20,21}$ One therapeutic option to interfere with Rho signaling are HMG-CoA reductase inhibitors (statins), which are widely used for cholesterol lowering purpose nowadays. They inhibit Rho signaling by depleting the cellular pool of isoprene precursor molecules, which are essential for C-terminal prenylation, correct intracellular localization and function of small GTPases. ${ }^{22}$ Notably, most of the pleiotropic functions of statins have been attributed to the inhibition of RhoA and Rac1. ${ }^{23-26}$ For instance, inhibition of Rac1 signaling by statins or small-molecule inhibitors of Rac1 mitigates radiationstimulated extravasation and metastasis in mice. ${ }^{27}$ Antimetastatic effects have also been ascribed to pharmacological inhibition of Rho-kinase (ROCK) in vivo. ${ }^{28}$ Moreover, pharmacological targeting of Rac1 and RhoA signaling has been suggested to protect normal cells and tissues from the deleterious effects of the anthracycline derivative doxorubi$\operatorname{cin}^{24}$ and ionizing radiation, ${ }^{29}$ respectively. Despite the bulk of in vitro data argueing for a key role of Rac1 in genotoxininduced stress responses, inflammation and cell death, its in vivo relevance for tissue specific stress responses and normal tissue damage following genotoxin-induced injury is largely unknown.

In the present study, we aimed to investigate the so far unknown in vivo relevance of Rac1 for hepatic responses to genotoxic insult by use of a genetic mouse model. Establishing the in vivo functions of Rac1 is hampered by early embryonic lethality of gene targeted mice. ${ }^{30}$ Here, we comparatively analyzed the acute and subacute doxorubicin and radiation response of transgenic $\mathrm{Rac1} 1^{\text {flox/flox/Mx1-Cre }}$ mice $^{18}$ that are characterized by a poly(l:C)-inducible Cre expression leading to a knockout of the rac1 gene in liver with that of corresponding control animals. The data obtained show that Rac1 deficiency has complex, both inhibitory and stimulatory, effects on doxorubicin-induced hepatic stress responses and tissue damage and, moreover, affects intrinsic liver aging. The results of our study provide first in vivo evidence that Rac1 is relevant for genotoxic stress responses and age-related processes in the liver.

\section{Results}

Characterization of poly(l:C)-induced knockout of rac1 in various tissues of $\mathrm{Rac} 1^{\text {flox/flox/Mx1-Cre }}$ mice. To generate mice characterized by a genetic knockout of the rac1 gene in liver, we made use of the Rac $1^{\text {flox/flox/Mx1-Cre }}$ strain described before. ${ }^{18}$ Three weeks after i.p. injection of poly(l:C), which leads to the induction of Cre expression, genomic DNA of liver and other organs was isolated and analyzed as to the recombinational knockout efficacy of the rac1 gene by genomic PCR. In addition, rac1 mRNA and Rac1 protein expression were analyzed by qRT-PCR and western blot analysis, respectively. Poly $(\mathrm{I}: \mathrm{C})$ treatment resulted in a $\geq 90 \%$ reduction of rac1 DNA in liver tissue (Figure 1a). In line with this, rac1 mRNA expression was also reduced by $\geq 90 \%$ (Figure 1b). Western blot-based analysis revealed a decrease of Rac1 protein expression by about $75 \%$ (Figure 1c), which was confirmed by immunohistochemical analysis (Figure 1d). Apart from liver, poly(l:C) mediated Cre-recombinase driven rac1 knockout was also observed in bone marrow, peripheral blood, lung, spleen, heart and kidney, whereas no clear rac1 deletion was detectable in the intestine and brain (Supplementary Table 3).

Hepatic rac1 knockout protects from acute doxorubicinbut not IR-induced DNA damage. DNA damage resulting from inhibition of topoisomerase II is considered as the most relevant anticancer effect of the anthracycline derivative doxorubicin $^{31,32}$ and might also be of relevance for normal tissue damage (i.e., of heart and liver) caused by anthracyclines. $^{24,33}$ Previously obtained in vitro and in vivo data indicated that Rac1 signaling is important for doxorubicininduced stress responses and cell death of endothelial cells as well as of heart and liver tissue. ${ }^{24,33-35}$ Here, we aimed to scrutinize this hypothesis using the aforementioned genetic mouse model, which is characterized by a poly(l:C)-inducible hepatic knockout of rac1. To investigate the influence of Rac1 on acute liver damage following doxorubicin treatment, S139 phosphorylation of histone $\mathrm{H} 2 \mathrm{AX}(\gamma \mathrm{H} 2 \mathrm{AX})$, which is a generally accepted marker of DNA double-strand breaks (DSBs), ${ }^{36-38}$ was monitored. As shown by both western blotbased analysis of $\gamma \mathrm{H} 2 \mathrm{AX}$ protein levels and immunofluorescence-based detection of $\gamma \mathrm{H} 2 \mathrm{AX}$ foci, we found that Rac1 deficiency significantly protects against doxorubicin-induced formation of DSBs as analyzed 48 and $96 \mathrm{~h}$ after single exposure to different doses of doxorubicin $(10 \mathrm{mg} / \mathrm{kg}$ BW and $15 \mathrm{mg} / \mathrm{kg} \mathrm{BW}$, respectively) (Figures $2 \mathrm{a}$ and $\mathrm{b}$ ). The genoprotective effect in the absence of Rac1 signaling was also observed $48 \mathrm{~h}$ after treatment with doxorubicin $(10 \mathrm{mg} / \mathrm{kg}$ ) by western blot (Supplementary Figure S1A). Taken together, Rac1 signaling is required for doxorubicin to provoke genotoxicity in an acute setting.

By contrast, IR-induced hepatic $\gamma \mathrm{H} 2 \mathrm{AX}$ phosphorylation, which was analyzed $72 \mathrm{~h}$ after total body irradiation (TBI) of mice with $6 \mathrm{~Gy}$, was not altered when rac1 was deleted (Figures 2c and d). The residual level of $\gamma \mathrm{H} 2 \mathrm{AX}$ foci was 0.8-1.2 foci/cell independent of the rac1 status of hepatocytes (Figure 2d). Also in non-irradiated animals, the number of hepatic $\gamma \mathrm{H} 2 \mathrm{AX}$ foci was very similar in wild-type ( $0.16 \mathrm{foci} / \mathrm{cell})$ and rac1-deficient $(0.13$ foci/cell) animals. The rac1 status also did not influence H2AX phosphorylation at earlier times following irradiation (i.e., $24 \mathrm{~h}$ ) (Supplementary Figure S1B). Overall, the data show that lack of rac1 does not cause a general hepatoprotection against the acute DNA damaging effects of genotoxins. Rather, genoprotection is specific for doxorubicin and does not comprise IR. Similar agent-specific differences have recently been observed following anthracycline and IR treatment of lovastatin pre-treated cells ${ }^{33,39}$ and animals. ${ }^{24,40}$

Effect of hepatic rac1 knockout on basal and genotoxic stress-induced mRNA expression. In order to investigate the consequences of rac1 knockout on basal and genotoxininduced mRNA expression of genes involved in the regulation of stress responses, a semi-customized PCR array was used. $^{24,41}$ This array enables the quantitative analysis of the mRNA expression of 94 selected genes involved in DNA repair, DNA damage response (DDR), cell-cycle progression and death (see Supplementary Table 2). Under normal (non-exposed) conditions, a total of nine genes was found to 
a
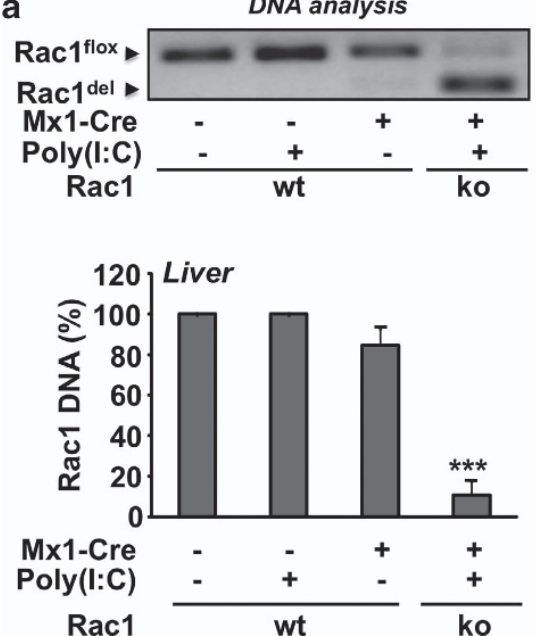

C
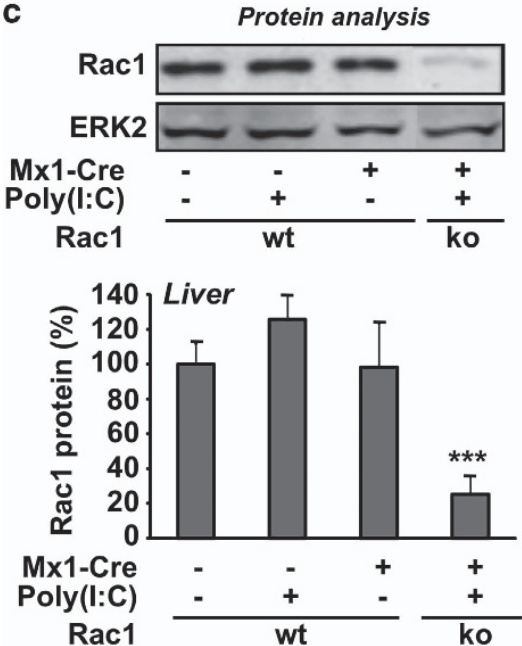

b
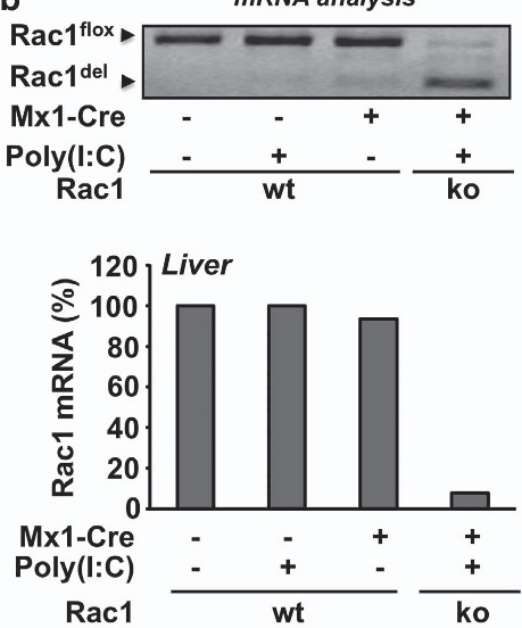

d

Immunohistochemistry

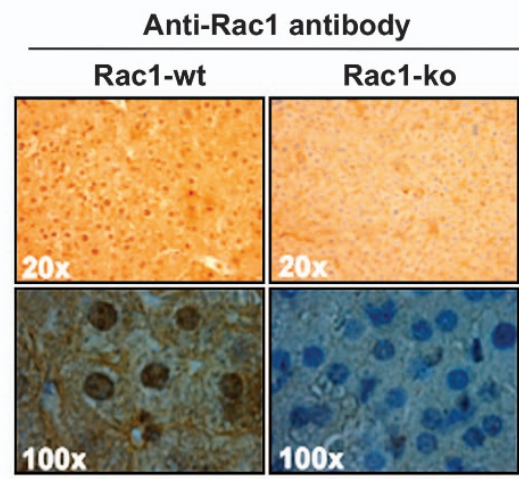

Figure 1 Efficacy of hepatic recombinational knockout of the rac1 gene following poly(l:C) treatment of transgenic Rac1 $1^{\text {flox/flox/Mx1-Cre }}$ mice. Rac ${ }^{\text {floxfllox }}$ mice either harboring the Mx1-Cre transgene $(\mathrm{Mx} 1-\mathrm{Cre}+)$ or not $(\mathrm{Mx} 1-\mathrm{Cre}-)$ were left untreated or were treated with poly $(\mathrm{l}: \mathrm{C})(3 \times 0.5 \mathrm{mg})$ as described in Materials and Methods. Three weeks later analyses were performed. DNA (a), mRNA (b) and protein (c) were prepared from liver and analyzed as to the presence of rac1 gene, rac1 mRNA and Rac1 protein, respectively, as described in Materials and Methods. (a, b) To calculate the efficiency of the rac 1 knockout on DNA and mRNA level, the total amount of DNA or mRNA was set to $100 \%$. (c) ERK2 protein expression was monitored as internal protein loading control and the level in the untreated control (i.e., non-poly(l:C) treated mice) was set $100 \%$. Quantitative data shown were obtained from $n=2(\mathrm{Mx} 1-\mathrm{Cre}-)$ or $n=3(\mathrm{Mx} 1-\mathrm{Cre}+)$ mice per group. For cDNA preparation, the mRNA samples isolated from the mice of each group were pooled. Arrows indicate the position of wild-type $\operatorname{rac1}\left(\right.$ Rac1 $\left.{ }^{\text {flox }}\right)$ and after Cre-mediated deletion/knockout of the rac1 gene $\left(\right.$ Rac1 $\left.{ }^{\text {del }}\right)$. ${ }^{* *} P<0.001$. (d) The amount of Rac1 protein in liver was analyzed by immunohistochemistry as described in Materials and Methods. Pictures were made with two different magnifications (top: $\times 20$; bottom $\times 100$ ). The result of one representative experiment is shown

be differently (i.e., $\leq 0.5$-fold or $\geq 2.0$-fold) regulated in liver tissue when rac1 knockout mice were compared with the control. These genes code for transcription factors (c-Jun, c-Fos), cell-cycle regulators (Ccne1 (=Cycline E)), chemokine receptor (Cxcr4), heat shock $70 \mathrm{kDa}$ protein $1 \mathrm{~B}$ (Hspa1b) and DNA repair related factors (Rad51, Topoll $\beta$, Wrn, Xpc) (Figure 3a). Next, we investigated the influence of Rac1 on the acute hepatic stress response provoked by genotoxins agents, that is, the anthracycline derivative doxorubicin and ionizing radiation (IR). As determined $48 \mathrm{~h}$ after i.p. injection of doxorubicin, Rac1 deficiency caused inhibition of doxorubicin-stimulated mRNA expression of cdkn1a (p21), hspa1b (Hsp701b), icam1 and topoll $\beta$ whereas it augmented the mRNA expression of the DNA repair gene rad51 and the cell-cycle-associated kinase wee1
(Figure 3b). Regarding IR-induced changes in gene expression following $24 \mathrm{~h}$ after TBI, Rac1 deficiency exclusively resulted in inhibitory effects, most notably IR-induced mRNA expression of the DNA repair genes fen 1 , topoll $\beta$, wrn and $x p c$, the cell-cycle regulatory genes cdkn1a (p21) and ccne1 (cycline E) and the heat shock gene hspa1b (Figure 3c). Taken together, rac1 knockout in liver affected both basal and acute genotoxic stress-induced mRNA expression of a subset of genes important for the regulation of cell-cycle progression, heat shock response and DNA repair. The gene encoding the heat shock $70 \mathrm{kDa}$ protein 1B (Hspa1b) showed altered hepatic mRNA expession in rac1-deficient mice under all experimental conditions tested.

Regarding the mRNA expression level of detoxifying factors, we observed a slightly reduced basal mRNA 
a
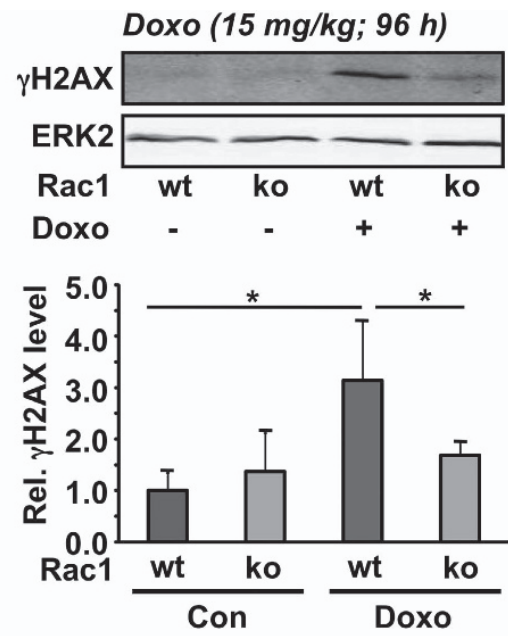

b
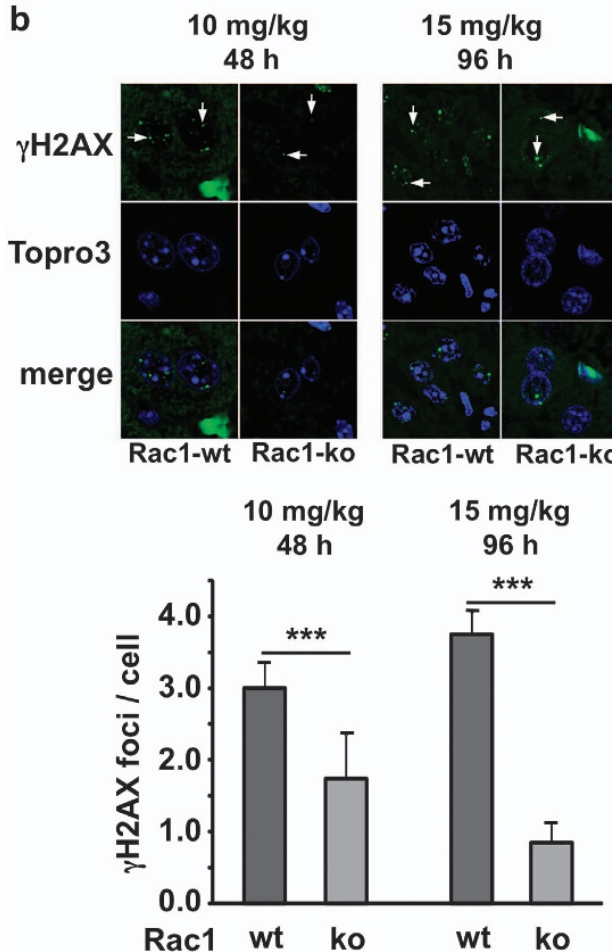

C
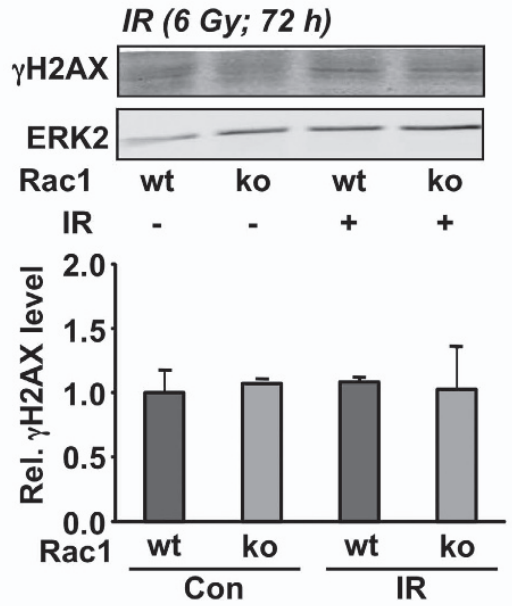

d

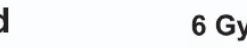

$6 \mathrm{~Gy}$
$24 \mathrm{~h}$

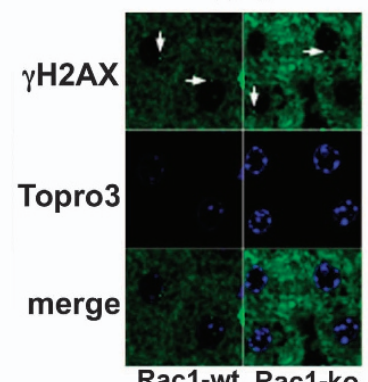

Rac1-wt Rac1-ko

Rac1-wt Rac1-ko

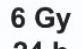

6 Gy

$24 \mathrm{~h}$

$72 \mathrm{~h}$

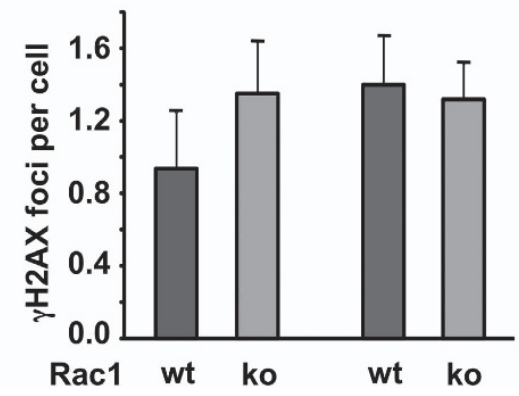

Figure 2 Influence of rac1 knockout on acute hepatic DNA damage induction following treatment of mice with doxorubicin or ionizing radiation. Rac1 $1^{\text {flox/flox/Mx1-Cre }}$ mice were left untreated or were treated with poly $(\mathrm{l}: \mathrm{C})(3 \times 0.5 \mathrm{mg})$ every other day in order to induce Cre-mediated hepatic knockout of rac1. Three weeks later, rac1 deleted (Rac1-ko) and wild-type (Rac1-wt) animals were exposed to a single high dose of doxorubicin (Doxo) (a, b) or were irradiated (TBI) (IR) (c, d). Rac1-wt, mice harboring wildtype rac1; Rac1-ko, mice with recombinational knockout of hepatic rac1. (a) Animals were treated with $15 \mathrm{mg} / \mathrm{kg}$ doxorubicin. After $96 \mathrm{~h}$, protein level of $\gamma \mathrm{H} 2 \mathrm{AX}$ was analyzed in whole liver extracts by western blot analysis. Quantitative data shown in the histogram are the mean \pm S.D. derived from the analysis of $n=3$ animals per group. ${ }^{\star} P<0.05$. (b) Forty eight and $96 \mathrm{~h}$ after treatment of mice with 10 and $15 \mathrm{mg} / \mathrm{kg}$ doxorubicin, respectively, the number of $\gamma \mathrm{H} 2 \mathrm{AX}$ foci was analyzed in liver tissue sections as described in Materials and Methods. Quantitative data shown in the histogram are the mean \pm S.D. from $n=3-4$ mice per group. ${ }^{* \star *} P<0.001$. (c) Animals were irradiated with 6 Gy. After $72 \mathrm{~h}$, protein level of $\gamma \mathrm{H} 2 \mathrm{AX}$ was analyzed in whole liver extracts by western blot analysis. Quantitative data shown in the histogram are derived from the analysis of $n=3$ animals per group. (d) Twenty four and $72 \mathrm{~h}$ after irradiation (6 Gy), the number of $\gamma \mathrm{H} 2 \mathrm{AX}$ foci was analyzed in liver tissue sections as described in Materials and Methods. Quantitative data shown in the histogram are the mean \pm S.D. from $n=3-4$ mice per group

expression of glutathione-S-transferase isoform mu1 (gstm1) in rac1 knockout animals as compared with the wild-type, whereas Nrf2-regulated heme oxygenase-1 (hmox-1) expression was unaltered (Figure 3d). gstm 1 and hmox-1 mRNA expression remained unaffected by the rac1 status following doxorubicin treatment (Figure $3 \mathrm{e}$ ). After IR treatment, hmox-1 mRNA levels were slightly enhanced in rac1 knockout mice
(Figure 3e). Basal mRNA expression of the drug transporter $m d r-1$ remained unchanged in the absence of rac1 (Figure 3d). Following doxorubicin and IR treatment, mdr1 mRNA expression was increased by about 8- to 12-fold in both wild-type and rac1 knockout mice (Figures $3 e$ and f). Similar results were obtained for the drug transporter Mrp1 (data not shown). Regarding acute pro-inflammatory and pro-fibrotic 

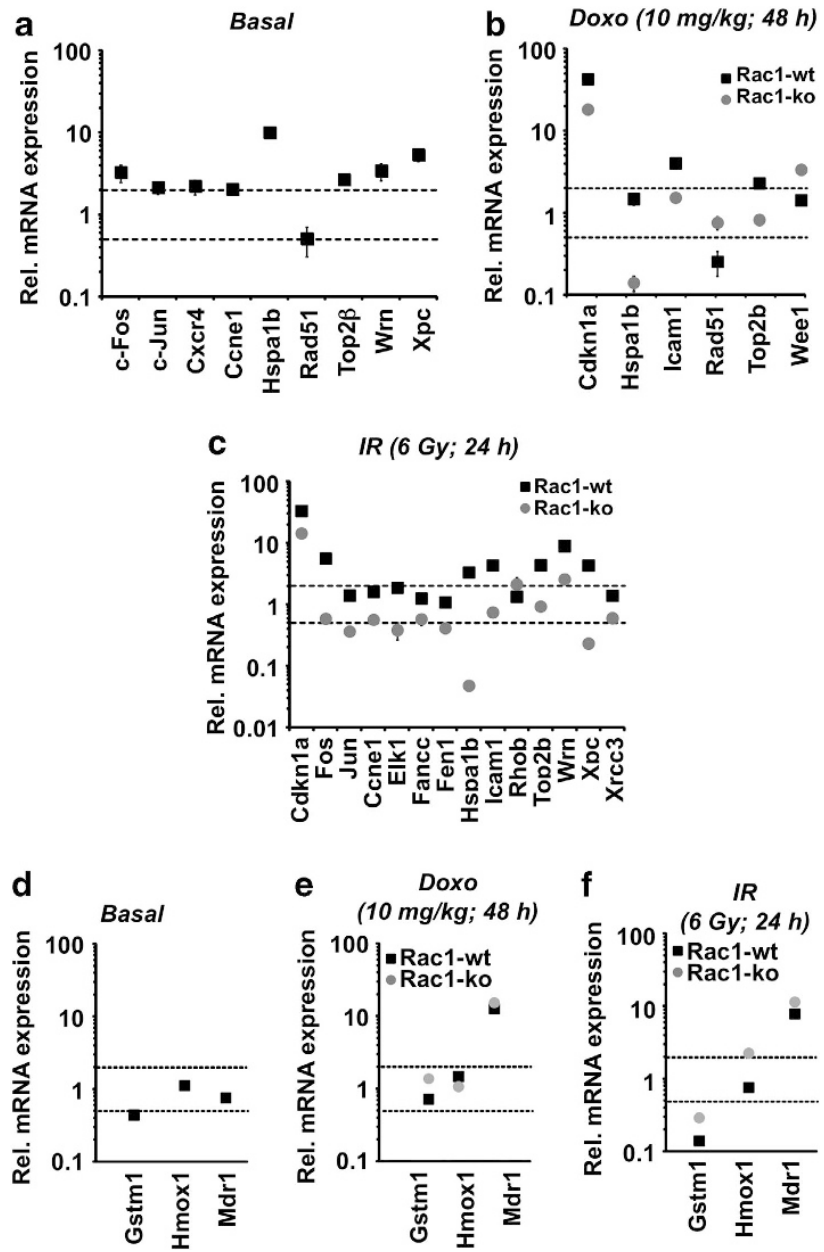

Figure 3 Loss of Rac1 modulates acute changes in gene expression induced by genotoxin exposure. Rac1 $1^{\text {floxfllox/Mx1-Cre }}$ mice were left untreated or were treated with poly(l:C) $(3 \times 0.5 \mathrm{mg})$ every other day. Three weeks later, control mice that harbor the rac1 gene (Rac1-wt) or mice deleted for rac1 (Rac1-ko) were either left untreated (a), were treated with $10 \mathrm{mg} / \mathrm{kg}$ doxorubicin (Doxo) and were sacrificed $48 \mathrm{~h}$ later (b) or were irradiated with $6 \mathrm{~Gy}$ (TBI) (IR) and sacrificed $24 \mathrm{~h}$ later (c) for qRT-PCR-based analysis of hepatic mRNA expression as described in Materials and Methods. For normalization mRNA levels of GAPDH and $\beta$-actin were used. Differences in gene expression of $\leq 0.5$-fold or $\geq 2$-fold (indicated with the dotted lines) between treated and non-treated groups were considered as relevant. Differences in gene expression of $>50 \%$ between Rac1-wt and Rac1-ko animals were also considered as relevant. Data shown are the mean \pm S.D. from triplicate determinations using CDNA synthesized from pooled RNA samples of $n=3-4$ mice per group. (a, d) Basal mRNA expression in the liver of rac1 knockout (Rac1-ko) animals was related to the expression in wild-type animals (Rac1-wt) which was set to 1.0. (b, $\mathbf{c}, \mathbf{e}, \mathbf{f})$ Analysis of mRNA expression following genotoxin exposure was performed as described above. Relative mRNA levels in corresponding nongenotoxin-treated controls was set to 1.0

hepatic stress responses following radiation treatment, no major effects of rac1 deletion on the mRNA levels of IL-6, TGF $\beta$ and CTGF, which were analyzed 24 or $72 \mathrm{~h}$ after irradiation, were found (Supplementary Figure S2).

Rac1 influences subacute doxorubicin-induced DNA damage in liver. Next, we addressed the question of whether Rac1 deficiency also protects the liver from subacute damage resulting from repeated exposure to doxorubicin. To this end, mice were treated with three single low $(3 \times 4 \mathrm{mg} / \mathrm{kg} \mathrm{BW}$ or $3 \times 6 \mathrm{mg} / \mathrm{kg}$ BW; i.p. injection once per week) doses of doxorubicin and analyses were performed 1 week after the last treatment. Rac1 proficient and deficient mice did not differ with respect to body and liver weight (Supplementary Figure S3). Opposed to the acute model, the level of $\gamma \mathrm{H} 2 \mathrm{AX}$ was increased in rac1-deficient mice in the subacute setting (Figures $4 a$ and b), indicating that Rac1 protects the liver from subacute genotoxic effects of doxorubicin. The mitotic index, which was analyzed by calculating the number of phospho-histone H3 (Ser10)positive cells, was enhanced up to threefold in rac1 knockout mice (Figures $4 \mathrm{c}$ and $\mathrm{d}$ ), pointing to a higher level of regenerative proliferation in Rac1-deficient liver tissue. The basal frequency of pH3-positive cells was similar in wild-type (3.6 $\mathrm{pH} 3$ positive cells $/ \mathrm{mm}^{2}$ ) and rac1 knockout mice (3.4 pH3 positive cells $/ \mathrm{mm}^{2}$ ). In the subacute model, doxorubicin treatment caused a slight increase in the number of TUNEL-positive cells in wild-type animals. Rac1 knockout mice showed a moderately enhanced (30-40\%) basal frequency of TUNEL-positive cells, which was not further enhanced following doxorubicin treatment (Figures $4 \mathrm{e}$ and $\mathrm{f}$ ). Assaying the frequency of cell death 72 and $96 \mathrm{~h}$ after single IR and doxorubicin treatment, respectively, rac1 knockout animals revealed a slightly elevated number of apoptotic cells as compared with wild-type mice (Supplementary Figure S4).

Effect of rac1 on doxorubicin-induced acute and subacute pro-fibrotic responses. Previously, inhibitory effects of statins on both radiation and doxorubicin-induced pro-fibrotic stress responses were reported. ${ }^{24,25,35,42}$ Bearing these reports in mind, we analyzed the consequences of hepatic rac1 deletion on acute and subacute pro-fibrotic responses. Lack of rac1 protected the liver from acute profibrotic responses observed $96 \mathrm{~h}$ after doxorubicin treatment. This is reflected by a reduced mRNA expression of the pro-fibrotic cytokine connective tissue growth factor (CTGF) and $\alpha$ smooth muscle actin ( $\alpha \mathrm{SMA}$ ) (Figure 5a). Doxorubicininduced mRNA expression of TGF $\beta$ (Figure 5a) and the pro-inflammatory cytokine IL-6 (Supplementary Figure S5A) were enhanced in rac1-deficient liver tissue. Tissue sections prepared from rac1 knockout animals also revealed higher reactivity towards antibody detecting myeloperoxidase (MPO), which is indicative of ongoing inflammatory processes (Supplementary Figure S5C). Moreover, in the acute setting (i.e., $96 \mathrm{~h}$ after exposure), hepatic rac1 deletion mitigated fibrotic tissue remodeling as detected by Masson's-Goldner trichrome staining of liver sections (Figure 5c).

Assaying subacute hepatotoxicitiy induced by doxorubicin, we observed that lack of rac1 promotes fibrotic events, such as the mRNA expression of the pro-fibrotic cytokine CTGF and $\alpha$ SMA (Figure $5 \mathrm{~b}$ ) as well as of TGF $\beta$ and type I collagen (Figure $5 b$ ). Basal mRNA expression of collagen I was elevated by threefold in the absence of rac1 (Figure 5). A tendential increase in fibrotic tissue remodeling was also detected by trichrome staining of liver sections (Figure $5 \mathrm{c}$ and $5 \mathrm{~d})$. Moreover, the mRNA level of the inflammatory cytokine interleukin-6 (IL-6) was higher in rac1 knockout mice as compared with the wild-type following repeated doxorubicin treatment (Supplementary Figure S5B). 
a
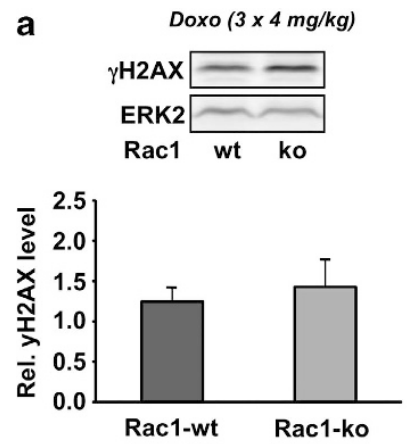

C
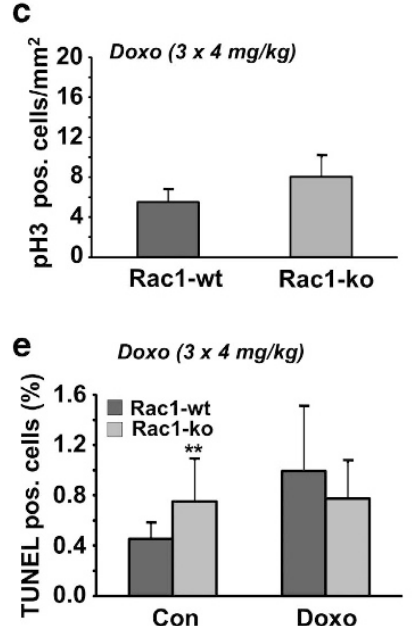

b
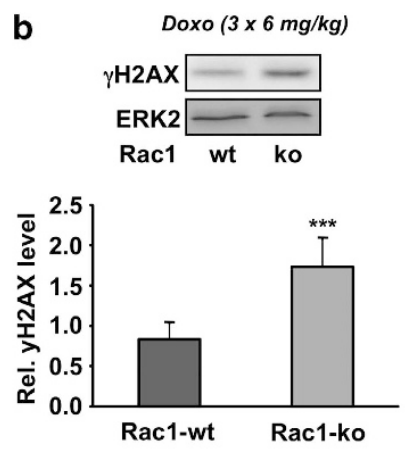

d
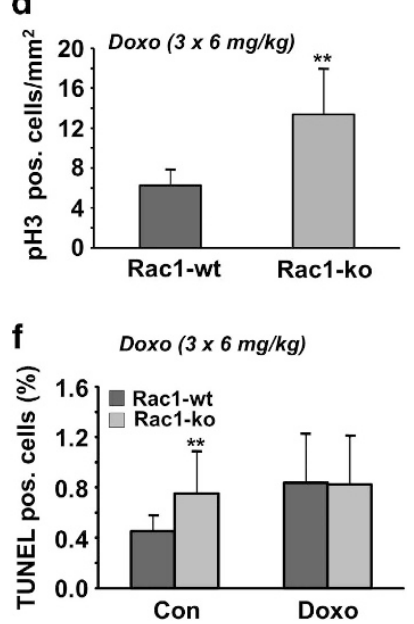

Figure 4 Influence of rac1 knockout on subacute stress responses following doxorubicin treatment. (a, b) Rac1 wild-type and rac1 knockout mice were repeatedly treated with doxorubicin $(3 \times 4 \mathrm{mg} / \mathrm{kg}$ (a) or $3 \times 6 \mathrm{mg} / \mathrm{kg}(\mathbf{b})$; one application per week) as described in Materials and Methods. In all, 21 days after the first injection of doxorubicin ( = 1 week after the last injection) liver was isolated for analysis. H2AX phosphorylation was measured in whole liver extracts by western blot analysis as described in Materials and Methods. Data shown are the mean \pm S.D. from $n=5-6$ mice per group. ${ }^{* \star *} P<0.001$. (c, d) Mitotic index was determined in liver tissue sections by analysis of the frequency of phospho-histone $\mathrm{H} 3$ (pH3) positive cells. Data shown are the mean \pm S.D. from $n=5-6$ mice per group. ${ }^{* *} P<0.01$. (e, f) The frequency of TUNEL-positive cells was calculated as described in Materials and Methods. Data shown are the mean \pm S.D. from $n=5-6$ mice per group. ${ }^{\star \star} P \leq 0.01$

Taken together, the biological consequences of hepatic rac1 knockout following treatment with doxorubicin depends on whether acute or subacute toxicity are analyzed. Rac1 deficiency protects the liver against acute geno- and cytotoxiticy of a single high dose of doxorubicin, whereas it promotes subacute toxic effects of the anthracycline observed after repeated exposure and longer post-incubation times. Therefore, we conclude that Rac1-regulated signaling ameliorates acute geno- and cytotoxicity after doxorubicin treatment, while it protects against the subacute hepatotoxic effects observed after repeated administration of the anthracycline.

Rac1 is involved in the regulation of age-related processes in the liver. Bearing in mind the pleiotropic

biological functions of Rac1, we asked the question whether Rac1 might influence intrinsic age-related processes in the liver. To address this question, animals were comparatively analyzed 3 weeks or 15 months after poly $(\mathrm{I}: \mathrm{C})$ induced deletion of the rac1 gene in liver. For control, mice that have not obtained poly $(\mathrm{I}: \mathrm{C})$ injection (= wild-type) were used. Analysis of the rac1 status in Rac1 $1^{\text {flox/flox-Mx1-Cre }}$ mice treated or not with poly $(\mathrm{I}: \mathrm{C})$ revealed that also in the non-treated (wild-type) animals part of the rac1 gene became deleted with age. The age-related partial deletion of the rac1 gene in the absence of poly $(\mathrm{I}: \mathrm{C})$ induced Cre expression (Figure 6a) discloses a partial leakiness of the Mx1-Cre system.

Analyzing body weight of rac1 ko and wild-type animals, no significant differences were observed in the course of the observation period of 15 months (data not shown). Also, the ratio of organ/body weight, which was analyzed 15 months after poly(I:C)-induced recombinational knockout, was similar in rac1 wt and rac1 ko animals (Figure 6b). Histopathological analysis showed that fibrotic tissue remodeling was significantly enhanced in rac1 knockout animals and further increased with age in mice lacking hepatic rac1 gene (Figures $6 c$ and d). Notably, protein expression of the senescence-related marker p16 was also largely enhanced when rac1 was deleted (Figure 6e). The mRNA expression profile also revealed differences in age-related processes between rac1 proficient and deficient animals. For incidence, the mRNA levels of the fibrosis-associated factors CTGF, TGF $\beta$, collagen type I and $\alpha$ SMA increased with age in both rac1 ko and wild-type animals (Figure 7). As CTGF mRNA expression was reduced in both young and old rac1 knockout mice and TGF $\beta$ expression was largely unaltered (Figure 7a), the observed increase in fibrosis in the absence of rac1 (see Figure 6d) likely does not rest on a stimulated expression of pro-fibrotic cytokines. mRNA expression of type I collagen was found to be enhanced in the absence of rac1 (Figure 7b), while expression of matrix metalloproteinase 1 (MMP1) was reduced in rac1 ko animals (Figure 7c). The Rac1 status did not affect the mRNA expression level of the tissue inhibitor of matrix metalloproteinases 2 (TIMP2) (Figure 7c). Taken together, the data indicate that increased expression of collagen I and concomitantly reduced expression of MMPs favors fibrotic remodeling of liver tissue in rac1 ko animals. Regarding inflammatory processes, we observed a two- to threefold increase in the mRNA level of IL-6 in elder wild-type animals but not in rac1-deficient mice (Figure 7d), indicating that rac1 is required for IL-6 mRNA expression. Moreover, deletion of rac1 for an extended period of time (i.e., 15 months) results in the appearance of large areas (conglomerates) of MPO-positive cells (Figure 7e). These conglomerates are less frequent and much smaller in elder rac1 proficient animals (Figure 7e). As a further marker of liver integrity, we monitored the serum level of liver transaminases GPT and GLDH. As compared with rac1 wild-type mice, we found higher levels of GPT and GLDH in the serum of both young and old rac1 ko mice (Supplementary Table 4). Analysis of the serum level of urea and creatinine, which are indicative of kidney damage, was included for control and did not reveal any differences related to the rac1 status of the animals (Supplementary Table 4). 

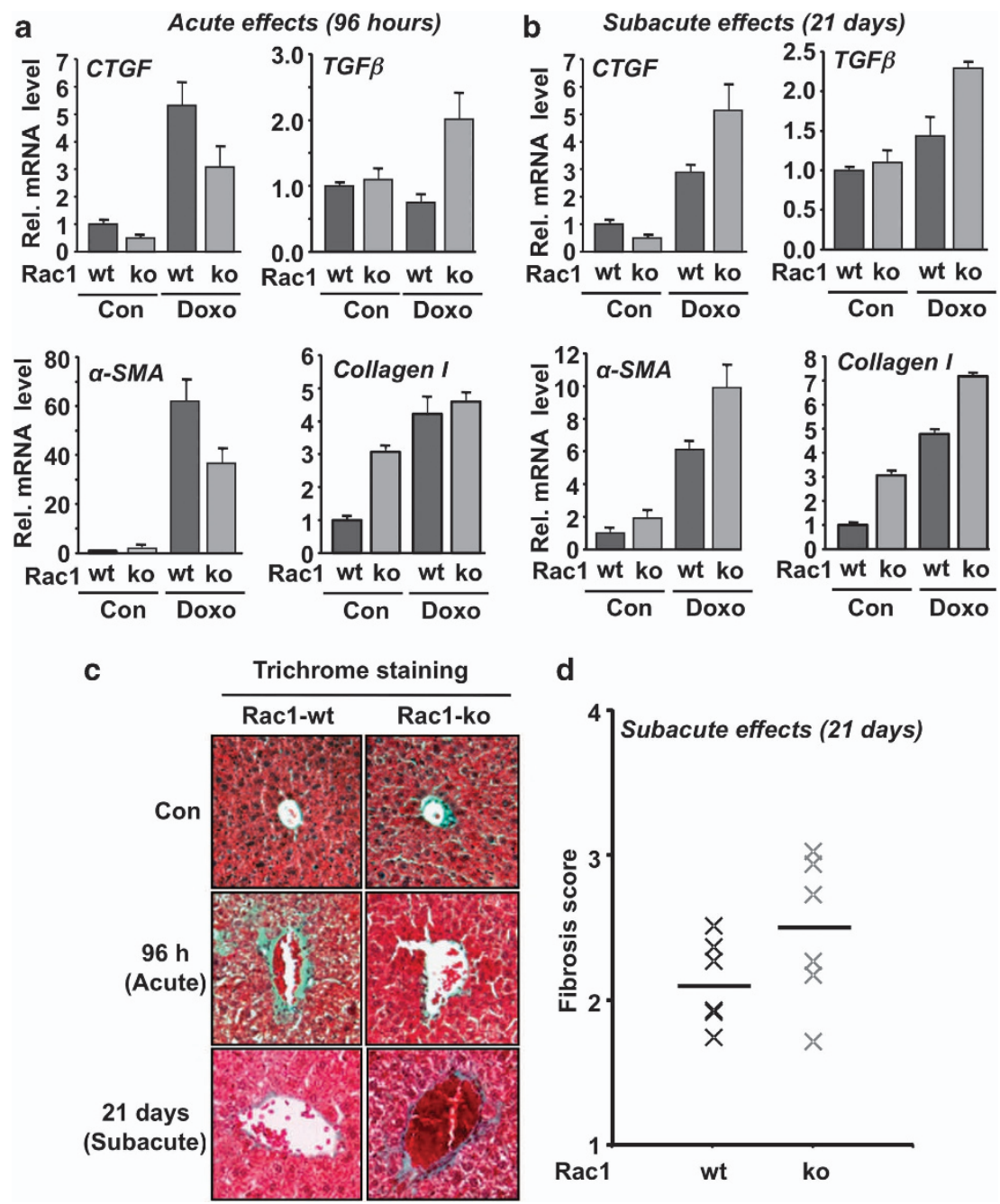

Figure 5 rac1 influences doxorubicin-induced acute and subacute pro-fibrotic stress responses. (a, b) Rac1 expressing (Rac1-wt) or rac1 deleted (Rac1-ko) animals were treated with a single high dose of doxorubicin (15 mg/kg) (Doxo) and analyzed $96 \mathrm{~h}$ later (a) (acute effects) or were repeatedly treated with doxorubicin $(3 \times 6 \mathrm{mg} / \mathrm{kg})$ and sacrificed 21 days after the first injection (b) (subacute effects). mRNA expression level of selected marker of fibrosis (TGF $\beta$, CTGF, $\alpha$ SMA, collagen I) was analyzed by qRT-PCR. Relative mRNA expression was normalized to the mRNA levels of GAPDH and $\beta$-actin and set to 1.0 in non-treated animals. Data shown are the mean \pm S.D. from triplicate determinations using cDNA generated from pooled RNA samples of $n=3-6$ mice per group. (c, d) For detection of fibrotic tissue remodeling, trichrome staining (Masson-Goldner) was accomplished as described in Materials and Methods. (c) The photograph shows a representative result. (d) Fibrosis score was analyzed under subacute setting as described in Materials and Methods. Quantitative data shown were obtained from $n=6$ mice per group. Horizontal bar represents the median

\section{Discussion}

Previously, we reported that the lipid lowering drug lovastatin protects human endothelial cells ${ }^{33}$ and rat cardiomyoblasts against the toxic effects of doxorubicin in vitro. ${ }^{24} \mathrm{We}$ also showed that it protects mouse liver and heart in vivo. ${ }^{24,35}$ These data together with the reports from other groups, ${ }^{43,44}$ let us hypothesize that inhibition of Rac1 signaling by statins reduces normal tissue damage evoked by anthracyclines. Inhibition of Rac1 signaling has also been suggested to be of importance for the cardioprotective effects of statins. ${ }^{26}$ Moreover, inhibition of Rho/Rac signaling by statins was demonstrated to be radioprotective in vivo. ${ }^{25,45}$ To scrutinize the relevance of Rac1 for genotoxin-induced responses in vivo, we made use of a Cre-LoxP-based knockout system, which enables an inducible recombinational deletion of the rac1 gene. ${ }^{18}$ We found that poly(I:C)-induced expression of Cre-recombinase results in a highly efficient $(\geq 90 \%)$ knockout of the rac1 gene in liver tissue. Not all tissues were equally responsive. The lowest levels of rac1 deletion were observed in intestine and brain.

Using this model, we investigated the biological consequences of hepatic rac1 deletion on acute doxorubicin- and IR-induced DNA damage formation. We found that the level of DNA damage following doxorubicin treatment was reduced in rac1 knockout animals, pointing to genoprotection in the absence of Rac1 signaling. This observation is in line with our previously reported statin-based in vitro and in vivo data. ${ }^{24,33-35}$ Notably, rac1 deletion does not protect from acute IR-induced formation of DNA damage, showing that genoprotection resulting from lack of Rac1 is not a general phenomenon, but rather specific for anthracyclines. This is in 

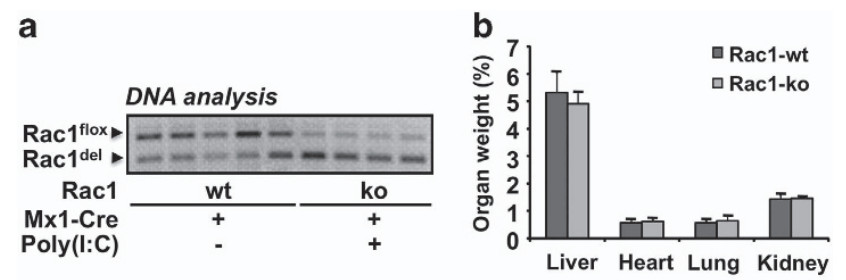

C
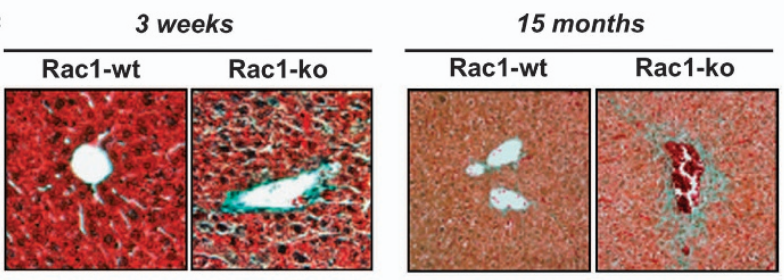

d

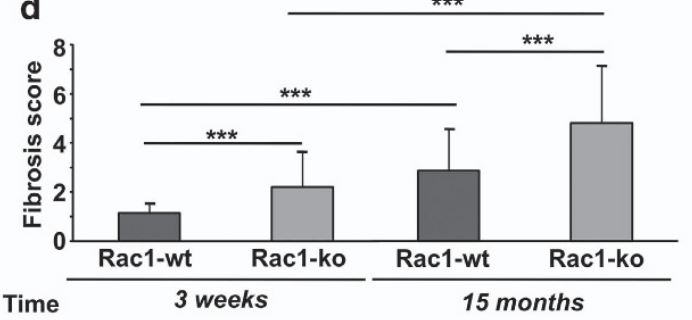

e

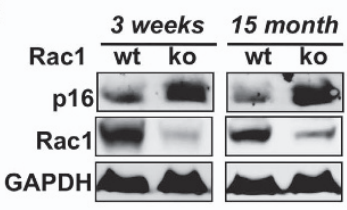

Figure 6 Long-term effects of rac1 knockout. Rac1 $1^{\text {flox/flox/Mx1-Cre }}$ mice were treated with poly $(\mathrm{l}: \mathrm{C})$ as described in Materials and Methods in order to delete rac1 in liver. Analyses were performed 3 weeks or 15 months later. (a) DNA was isolated from liver and the level of rac1 recombinational knockout was analyzed as described in Materials and Methods in several animals. (b) The weight of selected organs was determined and set into relation to total body weight. Each group started with six animals. Altogether, three animals died during the period of 15 months. Data shown are the mean \pm S.D. from $n=4$ (Rac1-ko) or $n=5$ (Rac1-wt) mice per group. Differences were statistically not significant. (c, d) Fibrotic tissue remodeling of blood vessels was analyzed 3 weeks and 15 months after poly(l:C) induced rac1 knockout by Masson-Goldner trichrome staining and fibrotic score was calculated as described in Materials and Methods. (c) Representative results; (d) quantitative data shown are the mean \pm S.D. from $n=4$ (Rac1-ko) or $n=5$ (Rac1-wt) mice. ${ }^{* * *} P<0.001$. (e) Protein expression of the senescence marker $p 16$ was analyzed in liver extracts of mice 3 weeks and 15 months after poly $(\mathrm{l}: \mathrm{C})$ induced deletion of rac1. For protein loading control, expression of GAPDH was analyzed. Relative p16 protein level in wild-type (wt) animals was set to 1.0. Left panel: representative result; right panel: mean \pm S.D. from $n=4$ animals per group

line with previous reports showing that lovastatin neither affects the initial nor the residual level of DSBs observed after IR exposure of endothelial cells in vitro ${ }^{39}$ or following TBI of mice. ${ }^{40}$ Taken together, these results strongly support the view that Rac1 is essential for doxorubicin-induced formation of DSBs in the liver. Data obtained with endothelial cells and cardiomyoblasts suggest that the genoprotective effect resulting from the absence of functional Rac1 is neither related to mechanisms of drug transport nor ROS. ${ }^{24,33}$ Accordingly, we report here that liver from rac1 knockout animals does not differ from control tissue with respect to the mRNA expression of the drug transporters Mdr-1 and Mrp-1 or defence functions such as heme oxygenase-1 (HO-1) and glutathione-S-transferase (Gstm1). PCR array-based analysis revealed that rac1 deletion caused complex alterations in the mRNA expression of the DNA repair factors Rad51, XPC and WRN, which are involved in DSB repair, nucleotide excision repair (NER) and base excision repair (BER), respectively. The biggest difference in gene expression between rac1 wild-type and rac1 ko animals was observed for the gene encoding the Hspa1b protein, which belongs to the family of Hsp70 proteins. The biological meaning of the differences in the mRNA expression patterns, which were observed under basal conditions and/or after treatment with doxorubicin and ionizing radiation, will be subject of forthcoming studies. Apart from reducing doxorubicin-stimulated hepatic DNA damage and mRNA expression of susceptibility-related factors, rac1 deficiency also had complex effects on acute pro-fibrotic stress responses stimulated by doxorubicin. As analyzed by Masson-Goldner staining, rac1 deletion caused a reduction of acute pro-fibrotic tissue remodeling processes. These data are, again, in line with reports obtained in vitro. ${ }^{24,40}$ Rac1 defect had no major consequences on IR-induced pro-fibrotic stress responses, indicating that the biological importance of Rac1 following acute genotoxic insults is agent specific.

Interestingly, as opposed to the acute setting, rac1 deletion enhanced the level of DNA damage and promoted fibrotic processes when mice were treated repeatedly with doxorubicin. Thus, Rac1 has protective functions regarding subacute liver damage evoked by repeated anthracycline treatment. Based on the data we suggest that the biological relevance of Rac1 for doxorubicin-induced hepatic stress responses varies with time: Rac1 promotes acute toxic effects of doxorubicin whereas it protects from its subacute toxicity. This is in contrast to what has been observed with lovastatin, which functions in a protective manner in both acute and subacute settings. ${ }^{24}$ Based on our in vivo findings presented here, we speculate that only acute protective effects of statins can be attributed to inhibition of Rac1 signaling. Protection from subacute anthracycline-induced toxicity by co-administration of statins might involve Rac1 independent mechanisms. Taking into account the data that have been obtained with ionizing radiation, ${ }^{29,42}$ it is tempting to speculate that additional inhibition of the Rho/ROCK pathway by statins is important for mitigating normal tissue damage caused by repeated exposure to doxorubicin.

It should be noted that the Mx1-Cre based poly(I:C)inducible knockout model does not allow a selective deletion of the rac1 gene in the liver only (see Supplementary Figure 3). This brings up the question whether poly(l:C)induced rac1 deletion in other tissues than the liver might have influenced hepatic fibrosis. There is no obvious rationale to assume that deletion of rac1 in spleen, lung, heart or kidney affects DNA damage induction and acute stress responses of the liver following doxorubicin treatment. However, appreciating a possible influence of rac1 deletion in cells of the hematopoietic system, in particular macrophages and neutrophils, for delayed (subacute) hepatic stress responses and fibrotic processes is more complex. Rac1 and Rac2 play 
a

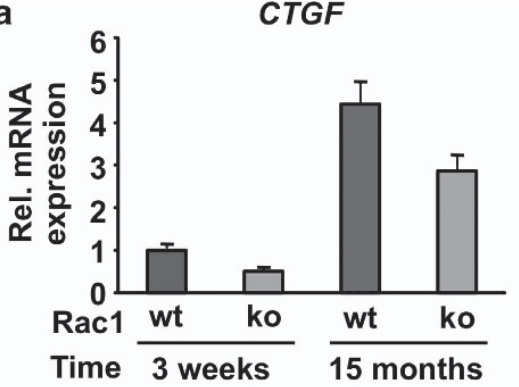

b

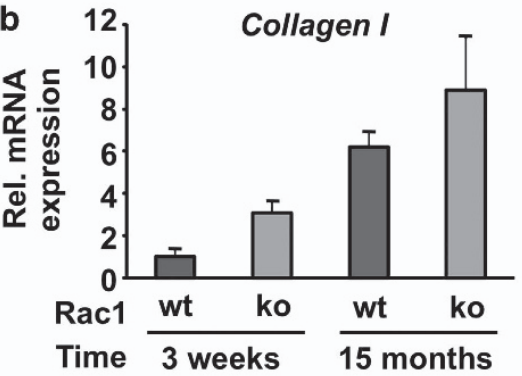

C

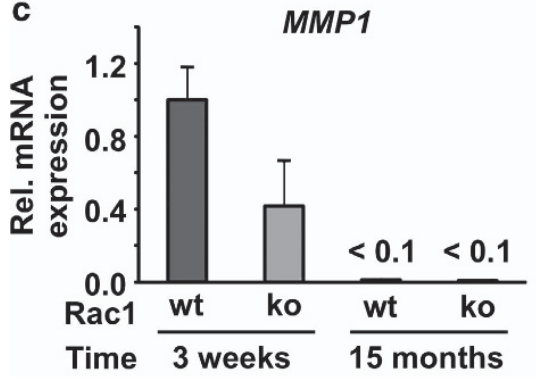

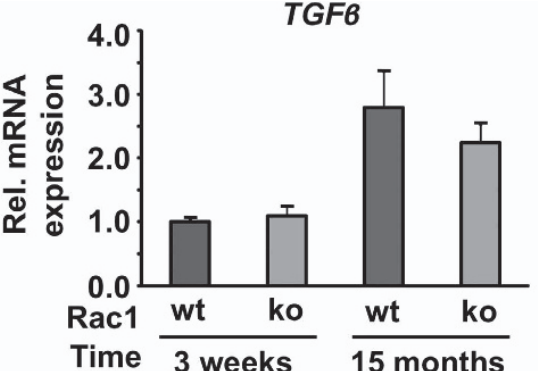
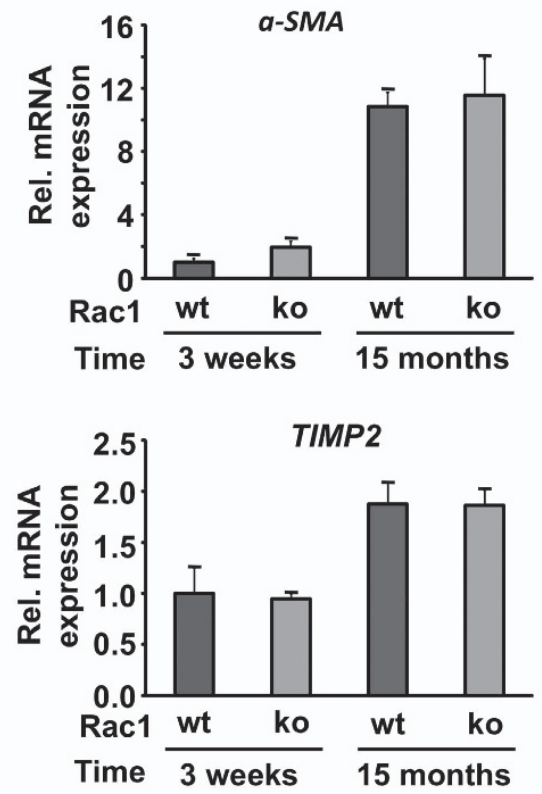
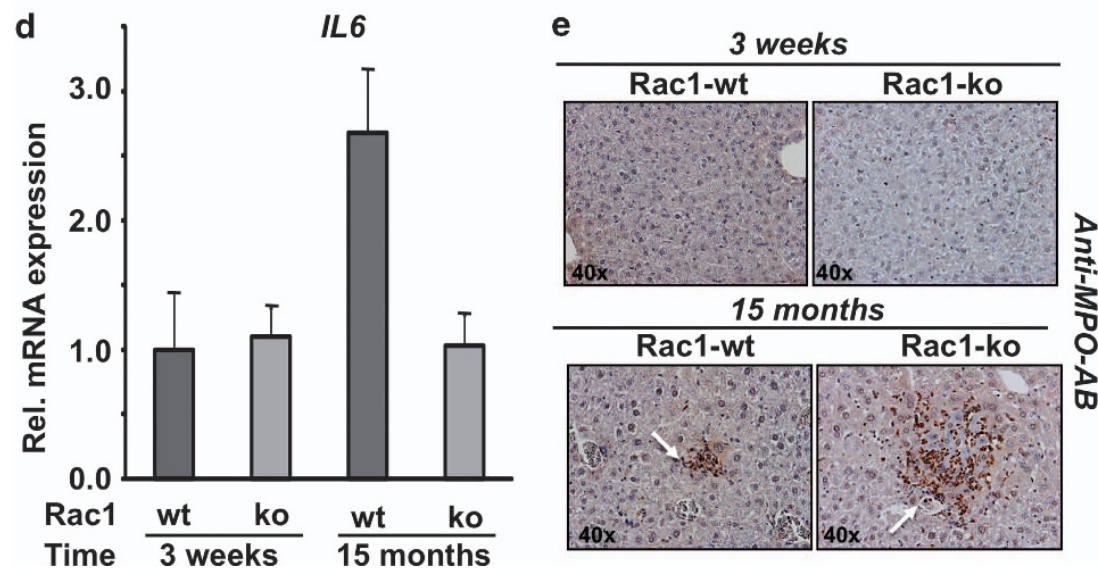

Figure 7 Loss of rac1 alters pro-fibrotic and pro-inflammatory gene expression as a function of time. (a-c) Rac1 $1^{\text {floxfllox/Mx1-Cre }}$ mice were treated with poly(l:C) as described in Materials and Methods in order to delete rac1 in liver. Animals were sacrificed 3 weeks or 15 months later and mRNA expression of the indicated genes was analyzed by qRT-PCR as described in Materials and Methods. Data shown are the mean \pm S.D. from triplicate determinations using cDNA generated from pooled RNA samples of $n=3-5$ mice per group. (a) Analysis of mRNA expression of pro-fibrotic cytokines. (b) Analysis of mRNA expression of fibroblast-derived pro-fibrotic factors. (c) Analysis of mRNA expression of factors involved in the regulation of matrix turnover. (d) mRNA expression of the pro-inflammatory cytokine IL-6 was analyzed by qRT-PCR as described in Materials and Methods. Data shown are the mean \pm S.D. from triplicate determinations using cDNA obtained from pooled RNA samples of $n=3-5$ mice per group. (e) Liver sections were stained with anti-MPO antibody. Representative results are shown

pivotal roles in the function of myeloid cells ${ }^{46,47}$ and are key players for B- and T-cell development. ${ }^{18,48}$ Moreover, Rac1 is essential for the function of neutrophils ${ }^{49}$ and affects cell spreading of macrophages, ${ }^{19,50}$ yet without influencing their migration. ${ }^{19}$ Taking into account these reports, we cannot rule out the possibility that rac1 deletion in particular cell types of the immune system (indirectly) influenced the subacute (delayed) hepatotoxicity of doxorubicin or the age-related alterations observed. To address this concern, analyses of transgenic mice that are characterized by a specific deletion of 
the rac1 gene in the liver, without concomitant rac1 deletion in cells of the immune system, is required. Therefore, we consider to include Rac1 ${ }^{\text {flox/flox/Alb-Cre }}$ mice into forthcoming studies.

Recently, small GTPases have been suggested to be involved in the regulation of the TOR complex, ${ }^{51}$ which determines life span. ${ }^{52}$ Moreover, insulin signaling plays a key role in aging and Rac1 is important for insulin secretion ${ }^{53}$ as well as insulin stimulated signaling. ${ }^{54}$ Keeping in mind these reports we asked the question whether rac1 deletion affects age-related processes. To this end, mice were analyzed at different time points (i.e., 3 weeks and 15 months) after poly(I:C)-induced rac1 deletion and compared to corresponding non-poly $(\mathrm{I}: \mathrm{C})$ treated controls. Both at early and late time points after rac1 deletion, Rac1-deficient mice revealed more signs of fibrosis than wild-type animals. Moreover, as compared with animals that lack rac1 for 3 weeks only, the expression of fibrotic markers was enhanced in mice lacking rac1 for 15 months. With increasing age, rac1 ko animals also showed hepatotoxicity as determined by the level of serum transaminases. In addition, the protein expression of the senescence-associated marker p16 was enhanced in rac1 deleted animals, supporting the view that anti-aging mechanisms are regulated in a Rac1 dependent manner.

Taken together, the data present the first in vivo evidence that the Ras-related GTPase Rac1 promotes acute and protects against subacute doxorubicin-induced stress responses of the liver and, moreover, counteracts processes that determine intrinsic hepatic aging.

\begin{abstract}
Materials and Methods
Mouse experiments. Mice were bred under specific pathogen-free conditions in the local animal housing facility at the University Medical Center Mainz (Germany). To study the in vivo functions of Rac1, we used

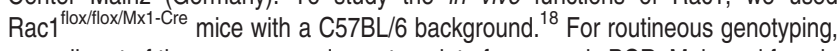
a small part of the ear was used as a template for genomic PCR. Male and female animals at 3-4 months of age were used for experiments. To induce rac1 knockout, transgenic mice were treated three times every other day with $0.5 \mathrm{mg}$ (i.p.) of synthetic double-stranded RNA polyinosinic-polycytidylic acid (poly(l:C)). Hepatic knockout confirmed 3 weeks after poly $(\mathrm{l}: \mathrm{C})$ treatment. For control, transgenic animals that have not been treated with poly(l:C) were used. For analyzing the biological consequences of rac1 deletion over time, Rac1 ${ }^{\text {floxflox/Mx1- }}$ ${ }^{C r e}$ mice were killed 3 weeks or 15 months after poly(l:C) injection and compared with corresponding non-poly $(I: C)$ treated controls. To study the influence of Rac1 on acute toxicity following genotoxin exposure, single treatment with doxorubicin ( $10 \mathrm{mg} / \mathrm{kg} \mathrm{BW}$, i.p. or $15 \mathrm{mg} / \mathrm{kg} \mathrm{BW}$, i.p.; analysis after 48 and $96 \mathrm{~h}$, respectively) or TBI (6 Gy (Cs-137 source); analysis 24 or $72 \mathrm{~h}$ later) was performed. Genotoxin treatment started 3 weeks after poly $(\mathrm{l}: \mathrm{C})$-induced Cre expression. To investigate subacute toxicity, doxorubicin treatment was performed once per week $(3 \times 4 \mathrm{mg} /$ $\mathrm{kg} \mathrm{BW}$, i.p. or $3 \times 6 \mathrm{mg} / \mathrm{kg} \mathrm{BW}$, i.p.) and analyses were done 3 weeks after the first doxorubicin injection. Different doxorubicin doses were used in order to address the aspect of dose-dependent responses. Group size was 3-6 animals per group. At the end of the experiments, organs were either fixed in $4.5 \%$ paraformaldehyde for (immuno)histological analyses or were frozen in liquid nitrogen for biochemical analyses. Also, blood samples were collected to determine blood cell count and serum parameters (routineously performed in the Institute of Clinical Chemistry and Laboratory Medicine of the University Medical Center Mainz, Germany).
\end{abstract}

Preparation of DNA and genomic PCR analysis. Genomic DNA from tissue samples was isolated with lysis buffer $(100 \mathrm{mM}$ Tris $\mathrm{pH} 8.5,200 \mathrm{mM} \mathrm{NaCl}$, $10 \mathrm{mM}$ EDTA, $0.2 \%$ SDS, $0.4 \mathrm{mg} / \mathrm{ml}$ proteinase $\mathrm{K}$ ). After overnight incubation at $55^{\circ} \mathrm{C}$, samples were heated $\left(95^{\circ} \mathrm{C}, 10 \mathrm{~min}\right)$ to inactivate proteinase $\mathrm{K}$. PCR reactions were performed using RED Taq ReadyMix (Sigma Aldrich, Steinheim, Germany) and specific primers (each $0.45 \mu \mathrm{M}$ ), which were created by use of
Primer3 software (primer sequence see Supplementary Table 1). After initial denaturation step $\left(95^{\circ} \mathrm{C}, 2 \mathrm{~min}\right), 30 \mathrm{PCR}$ cycles were performed $\left(95^{\circ} \mathrm{C}, 30 \mathrm{~s}\right.$; $\left.55^{\circ} \mathrm{C}, 30 \mathrm{~s} ; 72^{\circ} \mathrm{C}, 45 \mathrm{~s}\right)$. To terminate the reaction, samples were incubated at $72{ }^{\circ} \mathrm{C}$ for $10 \mathrm{~min}$. PCR products were analyzed by gel electrophoresis $(1.2 \%$ or $1.4 \%$ agarose gels) and visualized by ethidium bromide staining.

Total mRNA purification, preparation of CDNA and qRT-PCR analysis. To purify total mRNA from different tissues, the RNeasy Mini Kit (Qiagen, Hilden, Germany) was used according to the manufacturer's instructions. The RNA yield was determined by measuring the OD260/280 ratio with Nanodrop (Peqlab, Erlangen, Germany). RNA was isolated from $n=3-6$ animals per group and pooled for cDNA synthesis using the OmniScript Kit (Qiagen) according to the manufacturer's protocol. For each reaction, $2000 \mathrm{ng}$ of total mRNA was applied. For quantitative real-time PCR analysis, SensiMix SYBR \& Fluorescein Kit (Bioline, London, UK) and a MylQ Thermal Cycler (Bio-Rad, Munich, Germany) were used. The reactions were performed with $40 \mathrm{ng}$ of CDNA (1:10 dilution) and specific primers $(250 \mathrm{nM})$ according to the following protocol: $95^{\circ} \mathrm{C}, 10 \mathrm{~min}$; 45 cycles of $95^{\circ} \mathrm{C}, 15 \mathrm{~s} ; 55^{\circ} \mathrm{C} 15 \mathrm{~s} ; 72^{\circ} \mathrm{C}, 17 \mathrm{~s}$. At the end of each run, the melting curve was recorded to ensure the specificity of the reaction products. Amplicons with cycle thresholds $>35$ were excluded from analysis. Data were analyzed with iQ5 Optical System Software 2.0 (Bio-Rad). A semi-customized PCR-array facilitating the analysis of the mRNA expression of 94 genes related to DNA repair, stress signaling, cell-cycle regulation and cell death was used. ${ }^{41}$ mRNA expression levels were normalized to the amount of GAPDH and $\beta$-actin mRNA. To calculate drug-induced relative changes in mRNA levels, mRNA expression was related to that of corresponding controls which were set to 1.0. Alterations in relative mRNA expression of $\leq 0.5$ and $\geq 2.0$ were considered as different from control. mRNA expression data obtained from screening analyses were confirmed by separate qRT-PCR analyses performed in triplicate. Since cDNA generated from pooled RNA samples $(n=3-6)$ was used for qRT-PCR analyses, statistical analysis was omitted in these experiments. The sequences of the primers used are depicted in Supplementary Tables 1 and 2.

Preparation of protein extracts and western blot analysis. For preparation of total protein extracts, $15 \mathrm{mg}$ of corresponding tissue was homogenized by TissueLyser (Qiagen) in lysis buffer (Rotiload 1, Roth). The samples were sonicated and centrifuged $\left(10 \mathrm{~min}, 10000 \times \mathrm{g}, 4^{\circ} \mathrm{C}\right)$. The supernatant was removed, heated to $95^{\circ} \mathrm{C}$ and subjected to western blot analysis. To this end, proteins were separated by SDS-PAGE (10-15\% polyacrylamide gels) and transferred onto nitrocellulose membranes. After blocking in $5 \%$ non-fat milk in TBS $/ 0.1 \%$ Tween 20 for $60 \mathrm{~min}$ at room temperature, membranes were incubated with the primary antibody $\left(1: 100-1000\right.$; overnight at $\left.4{ }^{\circ} \mathrm{C}\right)$. After washing, incubation with infrared-labeled secondary antibody $(1: 2000,2 \mathrm{~h}$, room temperature) was performed. Bound antibodies were visualized using Odyssey Imager (LI-COR). The following antibodies were used: Rac1 (Millipore, Billerica, MA, USA), $\gamma$ H2AX (Epitomics, Burlingame, CA, USA), MPO (Abcam, Cambridge, UK), p16 (Santa Cruz, Santa Cruz, CA, USA), pH3 (Invitrogen, Paisley, UK), ERK2 (Santa Cruz).

Immunohistochemistry and immunofluorescence. Paraffinembedded tissues were cut into sections of $4 \mu \mathrm{m}$. Xylol was used to remove paraffin and sections were rehydrated by ethanol/ $\mathrm{H}_{2} \mathrm{O}$ gradient according to the standard procedure. Fibrotic tissue remodeling was detected by trichrome staining using the Masson-Goldner-Kit (Merck, Darmstadt, Germany). Fibrosis was scored according to the following criteria: 1 , no staining; 2 , weak staining; 3 , medium staining; 4 weak staining with infiltration; 5 , strong staining; 6 , medium staining with infiltration; 7, strong straining with infiltration; 8, strong staining with strong infiltration. To demask antigens for subsequent immunohistochemistry and immunofluorescence, rehydrated sections were incubated in Target Retrieval Solution (Dako, Hamburg, Germany) in a steam boiler for $40 \mathrm{~min}$. Subsequently, sections were blocked with Protein Block (Dako) for $120 \mathrm{~min}$ and incubated with primary antibody ( $1: 100 ; 4^{\circ} \mathrm{C}$; overnight). As secondary antibodies, HRP-coupled anti-rabbit/mouse (Dako) and Alexa Fluor 488-coupled anti-goat (Invitrogen, Darmstadt, Germany) antibody were used for immunohistochemistry and immunofluorescence, respectively. To visualize bound antibodies for immunohistochemistry Dako REAL EnVision Detection System (Dako) was used. For immunofluorescence, Vectashield (Vector, Burlingame, CA, USA), which includes the DNA staining dye DAPI, was applied. Tissue sections were evaluated microscopically (Olympus BX43; Olympus, Hamburg, Germany). 
Analysis of cell death and proliferation. To analyze the frequency of apoptotic liver cells the InSitu Cell Death Detection Kit (Roche Diagnostics, Mannheim, Germany) was used. The frequency of mitotic cells, which is indicative of proliferation, was determined by calculating the percentage of phospho-histone H3-positive cells. Three to five liver sections per animal were scored.

DNA damage analysis ( $\gamma \mathrm{H} 2 \mathrm{AX}$ foci analysis). Induction of DNA damage was detected by analyzing the level of $\mathrm{S} 139$ phosphorylation of histone $\mathrm{H} 2 \mathrm{AX}(\gamma \mathrm{H} 2 \mathrm{AX})$ by western blot analysis as well as by quantitation of the number of $\gamma \mathrm{H} 2 \mathrm{AX}$ foci per nucleus by immunofluorescence. Ser139 phosphorylated H2AX $(\gamma \mathrm{H} 2 \mathrm{AX})$ is a well accepted surrogate marker of DNA damage, in particular of DNA DSBs. ${ }^{36}$ For foci analysis, three to five liver sections per animal $(n=3-4$ animals per group) were evaluated for calculation of the mean number of $\gamma \mathrm{H} 2 \mathrm{AX}$ foci/nucleus.

Statistical analyses. For statistical analyses, student's t-test was used.

\section{Conflict of Interest}

The authors declare no conflict of interest.

Acknowledgements. We are very grateful to $\mathrm{VL}$ Tybulewicz ${ }^{18}$ for generously providing us with the Rac1 $1^{\text {floxfflox/Mx1-Cre }}$ mouse strain. We thank $\mathrm{R}$ Kitzinger, L Schumacher and T Brachetti for their excellent technical support. Furthermore, we thank K Lackner and A Schad for their support regarding blood cell count analysis and histopathological examination of liver sections, respectively. This work was supported by the Deutsche Forschungsgemeinschaft (DGF) (Fr 1241/8-1).

1. Bokoch GM. Regulation of cell function by Rho family GTPases. Immunol Res 2000; 21 $139-148$.

2. Hall A. Rho GTPases and the actin cytoskeleton. Science 1998; 279: 509-514.

3. Minden A, Lin A, Claret FX, Abo A, Karin M. Selective activation of the JNK signaling cascade and c-Jun transcriptional activity by the small GTPases Rac and Cdc42Hs. Cell 1995; 81: 1147-1157.

4. Coso OA, Chiariello M, Yu JC, Teramoto H, Crespo P, Xu N et al. The small GTP-binding proteins Rac1 and Cdc42 regulate the activity of the JNK/SAPK signaling pathway. Cell 1995; 81: 1137-1146.

5. Hordijk PL. Regulation of NADPH oxidases: the role of Rac proteins. Circ Res 2006; 98: 453-462.

6. Perona R, Montaner S, Saniger L, Sanchez-Perez I, Bravo R, Lacal JC. Activation of the nuclear factor-kappaB by Rho, CDC42, and Rac-1 proteins. Genes Dev 1997; 11 463-475.

7. Canman CE, Kastan MB. Three paths to stress relief. Nature 1996; 384: 213-214.

8. Mazars A, Tournigand C, Mollat $P$, Prunier C, Ferrand N, Bourgeade MF et al. Differential roles of JNK and Smad2 signaling pathways in the inhibition of c-Myc-induced cell death by TGF-beta. Oncogene 2000; 19: 1277-1287.

9. Ungefroren H, Groth S, Sebens S, Lehnert H, Gieseler F, Fandrich F. Differential roles of Smad2 and Smad3 in the regulation of TGF-beta1-mediated growth inhibition and cell migration in pancreatic ductal adenocarcinoma cells: control by Rac1. Mol Cancer 2011; 10: 67.

10. Hu Y, Hu X, Boumsell L, Ivashkiv LB. IFN-gamma and STAT1 arrest monocyte migration and modulate RAC/CDC42 pathways. J Immunol 2008; 180: 8057-8065.

11. Maroto $B, Y$ e MB, von Lohneysen K, Schnelzer A, Knaus UG. P21-activated kinase is required for mitotic progression and regulates Plk1. Oncogene 2008; 27: 4900-4908.

12. Halet G, Carroll J. Rac activity is polarized and regulates meiotic spindle stability and anchoring in mammalian oocytes. Dev Cell 2007; 12: 309-317.

13. Sandrock K, Bielek H, Schradi K, Schmidt G, Klugbauer N. The nuclear import of the small GTPase Rac1 is mediated by the direct interaction with karyopherin alpha2. Traffic 2010; 11: 198-209

14. Schmitz AA, Govek EE, Bottner B, Van Aelst L. Rho GTPases: signaling, migration, and invasion. Exp Cell Res 2000; 261: 1-12.

15. Kissil JL, Walmsley MJ, Hanlon L, Haigis KM, Bender Kim CF, Sweet-Cordero A et al. Requirement for Rac1 in a K-ras induced lung cancer in the mouse. Cancer Res 2007; 67 8089-8094.

16. Mulloy JC, Wunderlich M, Zheng Y, Wei J. Transforming human blood stem and progenitor cells: a new way forward in leukemia modeling. Cell Cycle 2008; 7: 3314-3319.

17. Mizukawa B, Wei J, Shrestha M, Wunderlich M, Chou FS, Griesinger A et al. Inhibition of Rac GTPase signaling and downstream prosurvival $\mathrm{Bcl}-2$ proteins as combination targeted therapy in MLL-AF9 leukemia. Blood 2011; 118: 5235-5245.

18. Walmsley MJ, Ooi SK, Reynolds LF, Smith SH, Ruf S, Mathiot A et al. Critical roles for Rac1 and Rac2 GTPases in B cell development and signaling. Science 2003; 302 459-462.
19. Wells CM, Walmsley M, Ooi S, Tybulewicz V, Ridley AJ. Rac1-deficient macrophages exhibit defects in cell spreading and membrane ruffling but not migration. J Cell Sci 2004; 117(Pt 7): 1259-1268.

20. Aznar S, Fernandez-Valeron P, Espina C, Lacal JC. Rho GTPases: potential candidates for anticancer therapy. Cancer Lett 2004; 206: 181-191.

21. Ellenbroek SI. Collard JG. Rho GTPases: functions and association with cancer. Clin Exp Metastasis 2007; 24: 657-672.

22. Liao JK, Laufs U. Pleiotropic effects of statins. Annu Rev Pharmacol Toxicol 2005; 45: 89-118.

23. Zhou Q, Liao JK. Pleiotropic effects of statins - basic research and clinical perspectives. Circ J 2010; 74: 818-826.

24. Huelsenbeck J, Henninger C, Schad A, Lackner KJ, Kaina B, Fritz G. Inhibition of Rac1 signaling by lovastatin protects against anthracycline-induced cardiac toxicity. Cell Death Dis 2011; 2: e190.

25. Haydont V, Bourgier C, Pocard M, Lusinchi A, Aigueperse J, Mathe D et al. Pravastatin Inhibits the Rho/CCN2/extracellular matrix cascade in human fibrosis explants and improves radiation-induced intestinal fibrosis in rats. Clin Cancer Res 2007; 13(18 Pt 1): $5331-5340$

26. Rashid M, Tawara S, Fukumoto Y, Seto M, Yano K, Shimokawa H. Importance of Rac1 signaling pathway inhibition in the pleiotropic effects of HMG-CoA reductase inhibitors. Circ J 2009; 73: 361-370

27. Hamalukic M, Huelsenbeck J, Schad A, Wirtz S, Kaina B, Fritz G. Rac1-regulated endothelial radiation response stimulates extravasation and metastasis that can be blocked by HMG-CoA reductase inhibitors. Plos One 2011; 6: e26413.

28. Itoh K, Yoshioka K, Akedo $\mathrm{H}$, Uehata M, Ishizaki T, Narumiya S. An essential part for Rho-associated kinase in the transcellular invasion of tumor cells. Nat Med 1999; 5 : 221-225.

29. Haydont V, Bourgier C, Vozenin-Brotons MC. Rho/ROCK pathway as a molecular target for modulation of intestinal radiation-induced toxicity. Br J Radiol 2007; 80: 32-40.

30. Sugihara K, Nakatsuji N, Nakamura K, Nakao K, Hashimoto R, Otani H et al. Rac1 is required for the formation of three germ layers during gastrulation. Oncogene 1998; 17: 3427-3433.

31. Gewirtz DA. A critical evaluation of the mechanisms of action proposed for the antitumo effects of the anthracycline antibiotics adriamycin and daunorubicin. Biochem Pharmacol 1999; 57 : 727-741.

32. Yan T, Deng S, Metzger A, Godtel-Armbrust U, Porter AC, Wojnowski L. Topoisomerase II\{alpha\}-dependent and -independent apoptotic effects of dexrazoxane and doxorubicin. Mol Cancer Ther 2009; 8: 1075-1085.

33. Damrot J, Nuebel T, Epe B, Roos WP, Kaina B, Fritz G. Lovastatin protects human endothelial cells from the genotoxic and cytotoxic effects of the anticancer drugs doxorubicin and etoposide. Br J Pharmacol 2006; 149: 988-997.

34. Huelsenbeck SC, Schorr A, Roos WP, Huelsenbeck J, Henninger C, Kaina B et al. Rac1 protein signaling is required for DNA damage response stimulated by topoisomerase II poisons. J Biol Chem 2012; 287: 38590-38599.

35. Henninger C, Huelsenbeck J, Huelsenbeck S, Grosch S, Schad A, Lackner KJ et al. The lipid lowering drug lovastatin protects against doxorubicin-induced hepatotoxicity. Toxicol Appl Pharmacol 2012; 261: 66-73.

36. Olive PL. Detection of DNA damage in individual cells by analysis of histone $\mathrm{H} 2 \mathrm{AX}$ phosphorylation. Methods Cell Biol 2004; 75: 355-373.

37. Kinner A, Wu W, Staudt C, lliakis G. Gamma-H2AX in recognition and signaling of DNA double-strand breaks in the context of chromatin. Nucleic Acids Res 2008; 36: 5678-5694.

38. Rogakou EP, Pilch DR, Orr AH, Ivanova VS, Bonner WM. DNA double-stranded breaks induce histone H2AX phosphorylation on serine 139. J Biol Chem 1998; 273: 5858-5868.

39. Nuebel T, Damrot J, Roos WP, Kaina B, Fritz G. Lovastatin protects human endothelial cells from killing by ionizing radiation without impairing induction and repair of DNA double-strand breaks. Clin Cancer Res 2006; 12: 933-939.

40. Ostrau C, Hulsenbeck J, Herzog M, Schad A, Torzewski M, Lackner KJ et al. Lovastatin attenuates ionizing radiation-induced normal tissue damage in vivo. Radiother Oncol 2009; 92: $492-499$

41. Fritz $G$, Henninger $C$, Huelsenbeck J. Potential use of HMG-CoA reductase inhibitors (statins) as radioprotective agents. Br Med Bull 2011; 97: 17-26.

42. Bourgier C, Haydont V, Milliat F, Francois A, Holler V, Lasser P et al. Inhibition of Rho kinase modulates radiation induced fibrogenic phenotype in intestinal smooth muscle cells through alteration of the cytoskeleton and connective tissue growth factor expression. Gut 2005; 54: 336-343

43. Yoshida M, Shiojima I, Ikeda H, Komuro I. Chronic doxorubicin cardiotoxicity is mediated by oxidative DNA damage-ATM-p53-apoptosis pathway and attenuated by pitavastatin through the inhibition of Rac1 activity. J Mol Cell Cardiol 2009; 47: 698-705.

44. Riad A, Bien S, Westermann D, Becher PM, Loya K, Landmesser U et al. Pretreatment with statin attenuates the cardiotoxicity of Doxorubicin in mice. Cancer Res 2009; 69: 695-699.

45. Haydont V, Gilliot O, Rivera S, Bourgier C, Francois A, Aigueperse J et al. Successful mitigation of delayed intestinal radiation injury using pravastatin is not associated with acute injury improvement or tumor protection. Int J Radiat Oncol Biol Phys 2007; 68: 1471-1482.

46. Didsbury J, Weber RF, Bokoch GM, Evans T, Snyderman R. rac, a novel ras-related family of proteins that are botulinum toxin substrates. J Biol Chem 1989; 264: 16378-16382. 
47. van Helden SF, Anthony EC, Dee R, Hordijk PL. Rho GTPase expression in human myeloid cells. PLOS One 2012; 7: e42563.

48. Guo F, Cancelas JA, Hildeman D, Williams DA, Zheng Y. Rac GTPase isoforms Rac1 and Rac2 play a redundant and crucial role in T-cell development. Blood 2008; 112: 1767-1775.

49. Glogauer M, Marchal CC, Zhu F, Worku A, Clausen BE, Foerster I et al. Rac1 deletion in mouse neutrophils has selective effects on neutrophil functions. J Immunol 2003; 170: 5652-5657.

50. Cox D, Chang P, Zhang Q, Reddy PG, Bokoch GM, Greenberg S. Requirements for both Rac1 and Cdc42 in membrane ruffling and phagocytosis in leukocytes. J Exp Med 1997; 186: $1487-1494$

51. Duran RV, Hall MN. Regulation of TOR by small GTPases. EMBO Rep 2012; 13: 121-128.

52. Lamming DW, Ye L, Katajisto P, Goncalves MD, Saitoh M, Stevens DM et al. Rapamycininduced insulin resistance is mediated by mTORC2 loss and uncoupled from longevity. Science 2012; 335: 1638-1643.
53. Wang Z, Thurmond DC. Differential phosphorylation of RhoGDI mediates the distinct cycling of Cdc42 and Rac1 to regulate second-phase insulin secretion. J Biol Chem 2010; 285: 6186-6197.

54. Ueda S, Kitazawa S, Ishida K, Nishikawa Y, Matsui M, Matsumoto H et al. Crucial role of the small GTPase Rac1 in insulin-stimulated translocation of glucose transporter 4 to the mouse skeletal muscle sarcolemma. FASEB J 2010; 24: 2254-2261.

(c) (i) $\odot$ Cell Death and Disease is an open-access journal published by Nature Publishing Group. This work is licensed under a Creative Commons Attribution-NonCommercialNoDerivs 3.0 Unported License. To view a copy of this license, visit http://creativecommons.org/licenses/by-nc-nd/3.0/

Supplementary Information accompanies this paper on Cell Death and Disease website (http://www.nature.com/cddis) 